\title{
Advances in detection methods for Shiga toxin-producing Escherichia coli (STEC)
}

\author{
Nora L. Padola * \\ Inmunoquímica y Biotecnología-CIVETAN-CONICET-CIC-FCV-Universidad Nacional del Centro de la Provincia de Buenos Aires, Tandil, Argentina \\ ${ }^{*}$ Correspondence: nlpadola@vet.unicen.edu.ar
}

Edited and reviewed by:

Elizabeth L. Hartland, The University of Melbourne, Australia

Keywords: Shiga toxin-producing E. coli, diagnosis, serotypes, virulence genes, RT-PCR

\section{A commentary on}

Detection of Shiga toxin-producing Escherichia coli in ground beef using Genedisc real-time PCR system

by Fratamico, P. M., and Bagi, L. K. (2012). Front. Cell Infect. Microbiol. 2:152. doi: $10.3389 /$ fcimb.2012.00152

Shiga toxin-producing Escherichia coli (STEC) comprise E. coli strains capable of producing toxins named Shiga toxin type 1 (Stx1), type 2 (Stx2), or both, encoded by $s t x 1$ and $s t x 2$ genes, respectively. Stx 2 is the most heterogeneous group possessing subtypes that differ in their association with human disease (Friedrich et al., 2002). Other typical virulence factors are intimin (encoded by eae gene), a plasmidencoded enterohemolysin and, in strains lacking eae, an autoagglutinating adhesin (Saa) (Paton and Paton, 2002; Blanco et al., 2004).

STEC are foodborne pathogens that have been associated worldwide with outbreaks and sporadic cases of hemolytic uremic syndrome (HUS) in children, STEC O157:H7 being the most notorious agent of the group. However, there are more than 400 non-O157 serotypes that have been involved in human disease and isolated from reservoirs of infection (Bettelheim, 2007; Rivas et al., 2010; Mora et al., 2011). It is important to note that not all non-O157 STEC have the capacity to cause HUS, which presents a public health problem to identify high-risk STEC.

STEC O157 and non-O157 have been isolated from meat, milk and dairy products, water, unpasteurized apple drinks, and vegetables. Additionally, direct contact with cattle and animal environment are currently considered as a source of transmission (Etcheverría and Padola, 2013).

Since 1982 when STEC O157:H7 was first reported, the selective diagnostic methods have used particular features of this serotype to increase its isolation. Because of the use of these selective methods, the prevalence of non-O157 STEC has been underestimated during several years. Both STEC O157 and non-O157 STEC have also been detected also using molecular methods that do not exert selection pressure toward any particular serotype, such as detecting stx in samples by PCR followed by isolation of colonies, detection of stx1, stx2, eae, saa, ehxA by multiplex PCR and serotyping (Scheutz et al., 2001; Fernández et al., 2010; Piazza et al., 2010) but this procedure is laborious and time consuming. PCR protocols have also been developed to detect particular serogroups and $\mathrm{H}$ antigens.

During 2012, Food Safety and Inspection Service (FSIS) determined the zero-tolerance policy for STEC O157:H7 including the top 6 non-O157 STEC serogroups in raw, nonintact beef products (Wang et al., 2013). Because of this, commercial test kits for screening from enrichment cultures based on immunological and molecular methods have been developed to detect stx, eae, and serogroups frequently associated with severe human disease $(\mathrm{O} 157, \mathrm{O} 26, \mathrm{O} 103$, O111, and O145). These enrichment samples could have individual bacteria or mixture of different bacteria harboring stx, eae, and serogroups that should be confirmed with isolation.

A large outbreak that ocurred in 2011 in Germany was caused by a strain O104:H4 harboring stx2. However, this strain was not a typical STEC because also carried a genome of enteroaggregative E. coli (EAEC) (Mellmann et al., 2011). stx genes are carried by lysogenic phages and could transfer to other bacteria by horizontal transfer. For this reason, STEC non-O157 are considered emerging pathogens that rapidly evolve and new serogroups of significant public health risk should be considered by diagnostic methods (Coombes et al., 2011). Indeed, the pathogenicity of STEC should not be restricted to a panel of serogroups or a single gene such as eae besides stx (EFSA Panel on Biological Hazards (BIOHAZ), 2013).

In order to evaluate a new PCR-real time technology based on simultaneous detection of multiple targets, Fratamico and Bagi (2012) have used a GeneDisc system. The GeneDisc consists of a disposable plastic disc of the size a compact disc with 36 microchambers preloaded with desiccated PCR primers and fluorescence labeled gene probes that use a GeneDisc cycler (Beutin et al., 2009). Fratamico and Bagi (2012) evaluated this technology to detect stx1, stx2, eae, ehxA, and O157 followed by a second GeneDisc assay targeting eight STEC serogroup: O26, O45, O91, O103, O111, O113, O121, O145 in ground beef. Notably, these authors have incorporated two important STEC serogroups: O91 and O113 that lack the eae gene but carry ehxA. Both serogroups have been related to HUS cases.

In this study two enrichment media were compared, buffered peptone water (BPW) recommended by GeneDisc and mTSB for STEC detection in the ground beef artificially inoculated. With both media, PCR results were similar and target genes were correctly identified with similar $\mathrm{Ct}$ values. Immunomagnetic separation (IMS) for serogroups O26, O45, O103, 
O111, O121, O145, O157, and plating onto Rainbow agar O157 were used and isolates were confirmed as the correct STEC serogroup. Serogroups O91 and O113 were not subjected to IMS and were more difficult to isolate on Rainbow Agar O157. All isolates were confirmed by conventional PCR targeting st 1 , st $x 2$, and eae. These authors have described the use of Rainbow Agar O157 for isolation of nonO157 because non-O157 strains produce colonies of different colors according to serogroup.

Fratamico and Bagi (2012) demonstrated that this technology is rapid, simple to use and suitable for screening ground beef and other foods, and could be adapted to detect other serogroups of high risk in public health.

\section{REFERENCES}

Bettelheim, K. A. (2007). The non-O157 shigatoxigenic (verocytotoxigenic) Escherichia coli; under-rated pathogens. Crit. Rev. Microbiol. 33, 67-87. doi: 10.1080/10408410601172172

Beutin, L., Jahn, S., and Fach, P. (2009). Evaluation of the GeneDisc real time PCR system for detection of enterohaemorrhagic Escherichia coli (EHEC) O26, O103, O111, O145 and O157 strains according to their virulence markers and thei $\mathrm{O}-$ and $\mathrm{H}$-antigen-associated genes. J. Appl. Microbiol. 106, 1122-1132. doi: 10.1111/j.13652672.2008.04076.x

Blanco, M., Padola, N. L., Sanz, M. E., Blanco, J. E., González, E. A., Dahbi, G., et al. (2004). Virulence genes and intimin types of Shiga-toxinproducing Escherichia coli isolated from cattle and beef products in Argentina. Int. Microbiol. 7, 269-276.

Coombes, B. K., Gilmour, M. W., and Goodman, C. D. (2011). The evolution of virulence in non-O157
Shiga toxin-producing Escherichia coli. Front. Microbiol. 2:90 doi: 10.3389/fmicb.2011.00090

EFSA Panel on Biological Hazards (BIOHAZ). (2013). VTEC-seropathotype and scientific criteria regarding pathogenicity assessment. EFSA J. 11:3138. doi: 10.2903/j.efsa.2013.3138

Etcheverría, A., and Padola, N. L. (2013). Shiga toxinproducing Escherichia coli: factors involves in virulence and cattle colonization. Virulence 4:5. doi: 10.4161/viru.24642

Fernández, D., Irino, K., Sanz, M. E., Padola, N. L., and Parma, A. E. (2010). Characterization of Shiga toxin-producing Escherichia coli isolated from dairy cows in Argentina. Lett. Appl. Microbiol. 51, 377-382. doi: 10.1111/j.1472-765X.2010.02904.x

Fratamico, P., and Bagi, L. K. (2012). Detection of Shiga toxin-producing Escherichia coli in ground beef using the GeneDisc real-time PCR system. Front. Cell. Infect. Microbiol. 2:152. doi: 10.3389/fcimb. 2012.00152

Friedrich, A. W., Bielaszewska, M., Zhang, W. L., Pulz, M., Kuczius, T., Ammon, A., et al. (2002). Escherichia coli harboring Shiga toxin 2 gene variants: frequency and association with clinical symptoms. J. Infect. Dis. 185, 74-84. doi: $10.1086 / 338115$

Mellmann, A., Harmsen, D., Cummings, C. A., Zentz, E. B., Leopold, S. R., Rico, A., et al. (2011). Prospective genomic characterization of the german enterohemorrhagic Escherichia coli O104:H4 outbreak by rapid next generation sequencing technology. PLoS ONE 6:e22751. doi: 10.1371/journal.pone.0022751

Mora, A., Herrera, A., López, C., Dahbi, G., Mamani, R., Pita, J. M., et al. (2011). Characteristics of the Shiga-toxin-producing enteroaggregative Escherichia coli O104:H4 German outbreak strain and of STEC strains isolated in Spain. Int. Microbiol. 14, 121-141. doi: 10.2436/20.1501.01.142

Paton, A. W., and Paton, J. C. (2002). Direct detection and characterization of Shiga toxigenic Escherichia coli by multiplex PCR for stx1, stx2, eae, ehxA, and saa. J. Clin. Microbiol. 40, 271-274. doi: 10.1128/JCM.40.1.271-274.2002
Piazza, R. M. F., Abe, C. M., Horton, D. S. P. Q., Miliwebsky. E., Chinen, I., Vaz, T. M. I., et al. (2010). "Detection and subtyping methods of Diarrheagenic Escherichia coli strains," in Pathogenic Escherichia coli in Latin America, ed A. G. Torres (Bolingbrook: Bentham Science), 95-115.

Rivas, M., Padola, N. L., Lucchesi, P. M. A., and Masana, M. (2010). "Diarrheagenic Escherichia coli in Argentina," in Pathogenic Escherichia coli in Latin America, ed A. G. Torres (Bolingbrook: Bentham Science), 348-392.

Scheutz, F., Beutin, L., and Smith, H. R. (2001). "Clinical detection of verocytotoxinproducing $E$. coli (VTEC)," in Verocytotoxigenic E. coli, eds G. Duffy, P. Garvey, and D. A. McDowell (Trumbull, CT: Food \& Nutrition Press, Inc.), 25-56.

Wang, F., Yang, Q., Kase, J. A., Meng, J., Clotilde, L. M., Lin, A., et al. (2013). Currents trends in detecting non-O157 Shiga toxin-producing Escherichia coli in foods. Foodborne Pathog. Dis. 10, 665-677. doi: 10.1089/fpd.2012.1448

Conflict of Interest Statement: The author declares that the research was conducted in the absence of any commercial or financial relationships that could be construed as a potential conflict of interest.

Received: 29 April 2014; accepted: 21 May 2014; published online: 05 June 2014.

Citation: Padola NL (2014) Advances in detection methods for Shiga toxin-producing Escherichia coli (STEC). Front. Microbiol. 5:277. doi: 10.3389/fmicb.2014.00277 This article was submitted to the journal Frontiers in Microbiology.

Copyright (C) 2014 Padola. This is an open-access article distributed under the terms of the Creative Commons Attribution License (CC BY). The use, distribution or reproduction in other forums is permitted, provided the original author(s) or licensor are credited and that the original publication in this journal is cited, in accordance with accepted academic practice. No use, distribution or reproduction is permitted which does not comply with these terms. 